\title{
New Laser Technologies for Diabetic Retinopathy
}

\author{
Natalia Fijalkowski · Darius M. Moshfeghi
}

Published online: 28 July 2013

(c) Springer Science + Business Media New York 2013

\begin{abstract}
Diabetic retinopathy is a leading cause of severe visual impairment for adults worldwide. Vision loss from systemic diabetes usually occurs secondary to macular edema or from de novo proliferation from the retinal vasculature. The Diabetic Retinopathy Study (DRS) established that panretinal photocoagulation (PRP) reduces the risk of severe vision loss from proliferative disease by $>50 \%$ and, thus, PRP has become the gold standard in the treatment of proliferative disease. The Early Treatment of DRS expanded the use of laser photocoagulation to clinically significant macular edema. Advances in laser technology have led to the development of semi-automated lasers, including pattern scanning laser $\left(\mathrm{PASCAL}^{\circledR}\right.$, Topcon) and fully automated lasers, such as the navigating lasers (NAVILAS ${ }^{\circledR}, \mathrm{OD} / \mathrm{OS}$ ), that aim to deliver faster, safer, more accurate, and less painful treatment of diabetic eye disease and other retinal conditions. Sublethal phototherapy with subthreshold diode micropulsed laser treatment for macular edema has led to a paradigm shift in our understanding of retinal photocoagulation by demonstrating similar efficacy with less collateral damage. Here, we review the current data on laser treatment of diabetic retinopathy with an emphasis on understanding the new laser photocoagulation technologies for treatment of proliferative diabetic retinopathy and clinically significant diabetic macular edema.
\end{abstract}

\footnotetext{
N. Fijalkowski · D. M. Moshfeghi $(\bowtie)$

Department of Ophthalmology, Horngren Family Vitreoretinal Center, Byers Eye Institute, Stanford University School of Medicine, 2452 Watson Court, Rm. 2277,

Palo Alto, CA 94303, USA

e-mail: dariusm@stanford.edu
}

Keywords Diabetic retinopathy - Laser therapy · Diabetic macular edema - Panretinal photocoagulation . Pattern scan laser $\cdot$ Navigated laser $\cdot$ PASCAL $^{\circledR}$. NAVILAS $^{\circledR} \cdot$ Subthreshold diode micropulsed laser

\section{Introduction}

Diabetic retinopathy is a microvascular complication of systemic diabetes and is a leading cause of vision loss in adults worldwide [1, 2]. Screening and treatment of diabetic eye disease is the most common reason for vitreoretinal specialist referral [3]. The prevalence of retinopathy among diabetics in the USA was $28.5 \%$ in 2008 [1]. The American Diabetes Association [4] recommends annual ophthalmic examinations with more frequent follow-up of high-risk patients. Management of diabetic retinopathy aims to prevent progression and treat established disease.

Prevention of vision loss is the most important step in management of patients with systemic diabetes and is accomplished through optimizing treatment of systemic conditions, addressing modifiable risk factors, and regular ophthalmic screening [5]. Studies have found poor glycemic control to be a risk factor for severe diabetic retinopathy and, thus, access to diabetes dietary counseling and regular medical care is critical $[6,7]$. Systemic conditions such as hypertension, dyslipidemia, nephropathy, pregnancy, and anemia are also risk factors for vision loss [7-10]. Ensuring patients are regularly followed by primary care physicians, have access to resources for optimal management of their medical conditions, and are counseled on modifiable risk factors such as smoking, can significantly reduce the progression and severity of diabetic eye disease [11-15].

Despite prevention efforts, patients often progress to more severe forms of diabetic retinopathy warranting 
intervention including clinically significant macular edema (CSME) and proliferative diabetic retinopathy (PDR). Two landmark trials established the vision-saving potential of laser photocoagulation for patients with advanced diabetic retinopathy: (1) The Diabetic Retinopathy Study (DRS) [16, 17], in which panretinal photocoagulation (PRP) demonstrated significant vision-saving potential for high risk PDR, and (2) Early Treatment of DRS (ETDRS), in which focal/ grid laser photocoagulation showed significant vision benefit in patients with CSME [18••]. These trials and subsequent studies established laser photocoagulation as one of the most efficacious first-line treatment for PDR and CSME. Recently, pharmacologic therapy with vascular endothelial growth factor (VEGF) inhibitors has demonstrated even greater vision benefit for CSME and will likely supplant macular laser photocoagulation as a front-line therapy.

Advances in laser technology have led to the development of semi-automated lasers, including pattern scanning laser (PASCAL ${ }^{\circledR}$, Topcon) and navigating lasers (NAVI$\left.\mathrm{LAS}^{\circledR}, \mathrm{OD} / \mathrm{OS}\right)$, that aim to refine the delivery of laser photocoagulation in a faster, safer, more accurate, and less painful way while minimizing adverse side effects. Sublethal phototherapy with subthreshold diode micropulsed (SDM) laser treatment for macular edema has led to a paradigm shift in our understanding of retinal photocoagulation by demonstrating similar efficacy with less collateral damage. Here, we will briefly discuss the treatment of diabetic retinopathy, and the traditional laser delivery models for PDR and CSME, and then review the newest automated lasers, including PASCAL ${ }^{\circledR}$ and NAVILAS ${ }^{\circledR}$, and SDM laser therapy. The purpose of this review is to update ophthalmologists on the newest laser therapies for treatment of diabetic retinopathy.

\section{Treatment of Diabetic Retinopathy}

Diabetic retinopathy usually manifests after years of systemic diabetes, but histological studies of the retina and its support cells reveal that microscopic changes are present well before clinical detection is possible [19-21]. Regular vigilant screening and evaluation of changes over time are the foundation of diabetic eye care. The first sign of any diabetic retinopathy is usually microaneurysms. Table 1 describes a simplified diabetic retinopathy classification scheme used in this review that is adapted from the ETDRS and the Wisconsin Epidemiological Study of Diabetic Retinopathy [6, 22, 23]. This is similar to the International Clinical Diabetic Retinopathy and Diabetic Macular Edema Severity Scales published by the Global Diabetic Retinopathy Project Group [24]. In general, diabetic retinopathy is classified as non-PDR (NPDR) or PDR, both of
Table 1 Classification of diabetic retinopathy

\begin{tabular}{|c|c|}
\hline Classifications & Definitions \\
\hline \multicolumn{2}{|c|}{ Non-proliferative diabetic retinopathy } \\
\hline Mild & $\begin{array}{l}\text { At least one microaneurysm } \\
\text { AND } \\
\text { Did not meet more severe criteria }\end{array}$ \\
\hline Moderate & $\begin{array}{l}\text { Microaneurysms/hemorrhage greater than } \\
\text { standard image } 2 \mathrm{~A}^{\mathrm{a}} \\
\text { OR } \\
\text { Cotton wool spots, intraretinal microvascular } \\
\text { abnormalities (IRMA), venous beading }\end{array}$ \\
\hline Severe (high-risk) & $\begin{array}{l}\text { Microaneurysms and/or hemorrhage greater } \\
\text { than standard image } 2 \mathrm{~A}^{\mathrm{a}} \text { in all four } \\
\text { quadrants } \\
\text { OR } \\
\text { IRMA greater than standard photograph } 8 \mathrm{~A}^{\mathrm{a}} \\
\text { OR } \\
\text { Venous beading in more than two quadrants }\end{array}$ \\
\hline $\begin{array}{l}\text { Very severe } \\
\quad \text { (high-risk) }\end{array}$ & Two or more of the severe criteria \\
\hline $\begin{array}{l}\text { Clinically } \\
\text { significant } \\
\text { macular edema }\end{array}$ & $\begin{array}{l}\text { Thickening of retina }<500 \mu \mathrm{m} \text { from macula } \\
\text { center } \\
\text { OR } \\
\text { Hard exudates and thickened retina }<500 \mu \mathrm{m} \\
\text { from center of macula } \\
\text { OR } \\
\text { Zone or retinal thickening at least one disk } \\
\text { area in size less than one disk away from } \\
\text { macula center }\end{array}$ \\
\hline Proliferative diabetic & retinopathy \\
\hline Early & $\begin{array}{l}\text { Presence of new vessels } \\
\text { AND } \\
\text { Did not meet high-risk or severe criteria }\end{array}$ \\
\hline High-risk & $\begin{array}{l}\text { New vessels on or within one disc diameter of } \\
\text { the optic disc }\left(>\text { standard photograph } 10 A^{\mathrm{a}}\right) \\
\text { OR } \\
\text { Vitreous or preretinal hemorrhage with new } \\
\text { vessels }\end{array}$ \\
\hline Severe & $\begin{array}{l}\text { Hemorrhage obscuring posterior pole } \\
\text { OR } \\
\text { Macular detachment }\end{array}$ \\
\hline
\end{tabular}

A variety of severity and classification schema for diabetic retinopathy have been proposed. For the purpose of this review, the above classification scheme represents a simple severity scale for evaluating new laser technology and other treatments for diabetic eye disease at varying levels of severity adapted from the ETDRS and the Wisconsin Epidemiological Study of Diabetic Retinopathy (WESDR) [6, 22, 23]. These are similar to the International Clinical Diabetic Retinopathy and Diabetic Macular Edema Severity Scales published by the Global Diabetic Retinopathy Project Group [24]. It is important to note that studies use different precise definitions for classifying diabetic retinopathy, and any interpretations made from their conclusions should be applied only to the disease severity as defined by the study

a Standard images refer to the references fundus photos in the Early Treatment of Diabetic Retinopathy Study (ETDRS) [18••, 84, 85] 
which can also have CSME that alters the recommended treatment. This review will not focus on the presentation, evaluation, classification, or diagnosis of different stages of diabetic eye disease, but will instead briefly summarize the current recommendations for treatment to set the stage for understanding the applications of new laser technologies.

\section{Non-proliferative Diabetic Retinopathy}

Vision loss from diabetic retinopathy is primarily via development of CSME or progression to proliferative disease. Mild and moderate NPDR without CSME should be carefully observed with regular follow-up, but no therapy is currently recommended. The ETDRS demonstrated vision benefit of early PRP for patients with severe and very severe NPDR without CSME [18••, 25]. The ETDRS also showed that eyes with CSME involving or threatening the center of vision are at high-risk of vision loss [26••]. Treatment of CMSE is a rapidly evolving field in ophthalmology with an ever-expanding role of intravitreal VEGF-inhibitors (ranibizumab, Genentech/ bevacizumab, Genentech/aflibercept, Regeneron) in the context of known long-term benefits of focal laser photocoagulation. We will not discuss these interesting developments here, but simply summarize the current state of knowledge on the treatment of CSME with NPDR.

Prophylactic laser treatment of macular edema that is not clinically significant is generally not recommended. When CSME does develop, the physician can administer intravitreal injections of VEGF-inhibitors, perform focal/ grid laser photocoagulation, or both [27-29, 30• 31-34]. Intravitreal corticosteroids and vitreous surgery are alternative therapies when the two first-line treatments fail. In the ETDRS, when focal laser photocoagulation was performed on eyes with CSME, the risk of moderate visual loss was decreased by $50 \%$ and many clinicians continue to treat in this manner [26••]. Recently, intravitreal $0.3 \mathrm{mg}$ ranibizumab (Lucentis, Genentech) was approved for the treatment of diabetic macular edema and trials have demonstrated short-term superior efficacy to focal/grid laser photocoagulation alone. The most effective treatment to date for CSME has been ranibizumab injections plus deferred focal laser therapy with a mean +2.9 more letters gained when compared to injection with prompt focal/laser therapy at 3 -year follow-up [35••]. Intravitreal corticosteroids have also demonstrated short-term benefit, but come with the added risks of exacerbating glaucoma and cataracts. In the presence of vitreomacular traction or failure of first-line treatments, vitreous surgery can be considered.

\section{Proliferative Diabetic Retinopathy}

The metabolic derangements in glucose are not well tolerated in the delicate retinal architecture and can cause reduced perfusion and local retinal ischemia. In response, angiogenic factors such as VEGF are released to increase the blood supply to the ischemic retina, but the chaotic growth of these new vessels does more harm than good; the de novo vessels directly impede vision, undergo fibrosis with membrane formation, and ultimately create traction of the posterior vitreous leading to hemorrhage and/or traction retinal detachment. PDR is an advanced stage of diabetic eye disease that can rapidly result in severe, irreversible vision loss [36]. Risk factors for PDR include duration of diabetes (25\% with type I disease and $16 \%$ with type II progress to PDR at 15 years), poor glycemic control, and type I diabetes [6, 37, 38].

The DRS showed that prompt PRP reduces vision loss in patients with high-risk PDR [39]. In cases where PDR is inadequately treated with PRP, then vitrectomy followed by laser ablation is recommended. Both the DRS and ETDRS showed that full scatter photocoagulation could exacerbate macular edema leading to moderate visual loss when done immediately [18••, 39]. When PRP is planned in eyes with CSME, then focal photocoagulation should be performed first followed with delayed PRP.

\section{Manual Lasers for Diabetic Retinopathy}

LASER is an acronym for light amplification by stimulated emission of radiation. The ability to use light from various sources, originally the sun, to photocoagulate the retina has been known for centuries. Over the last few decades, ophthalmologists have embraced the precision, speed, and ease of laser technology for the treatment of many disorders including diabetic retinopathy. By refining the spectrum of light, selecting specific wavelengths, varying pulse duration and, recently, adding automated components, a myriad of laser technologies are available to the practicing clinician.

Originally, the ETDRS involved argon laser applied directly to microaneurysms and areas of retinal thickening. Other historical lasers include the ruby $(694 \mathrm{~nm})$, argon $(488,514 \mathrm{~nm})$, and krypton $(647 \mathrm{~nm})$ lasers. These older lasers were effective for reducing vision loss, but came with many undesirable consequences such as pain, large areas of "thermal blooming", i.e. collateral photocoagulation of nearby tissues through heat diffusion in horizontal and vertical directions [40], and fibrosis of the disrupted retinal pigmented epithelium or other serious complications in rare cases [41]. Over time, laser technology has been refined to apply smaller, less intense, and less frequent burns. The most common lasers used today are the frequency-doubled Nd:YAG (532 nm, green light) and the yellow semiconductor laser $(577 \mathrm{~nm})$. 
Focal/Grid Photocoagulation for Clinical Significant Macular Edema

The Diabetic Retinopathy Clinical Research network (DRCR.net) [42] have summarized general guidelines for manual focal/grid laser administration. They recommend the direct treatment of all leaking microaneurysms in areas of retina thickening with a targeted $50-\mu \mathrm{m}$ direct spot treatment for $0.05-0.10 \mathrm{~s}$. Microaneurysm color change is not required, but a slight change with a gray-white burn may facilitate confirmation of accurate administration. For grid treatment, the physician should target all areas with edema that are not associated with microaneurysm with the same range as focal for superior, nasal, and interior quadrants of the macula and a slightly enlarged potential parameter in the temporal region $(500-3,500 \mu \mathrm{m})$. The target burn size and duration are the same as for focal, with ideally a light gray visible burn scar, separated from the other scar by two burn widths. The DRCR.net protocol is used for any yellow or green laser with lenses that increase or decrease the burn size by less than $10 \%$ [42].

\section{Panretinal Photocoagulation}

PRP is the indicated for high-risk PDR, rubeosis with or without neovascular glaucoma, PDR not involving the disc with capillary non-perfusion, and widespread retinal ischemia. The DRS and other studies have found PRP to reduce the cumulative risk of severe vision loss by more than $50 \%$ at 6 years [16, 17, 43, 44]. Regression of neovascularization occurs in $30-55 \%$ of eyes after PRP [16, 39]. Typical treatment includes $600-1,600$ burns on the retina, $500 \mu \mathrm{m}$ in size, in a confluent grid pattern for neovascularization not involving the optic disc.

Complications and adverse side effects can be significant drawbacks to PRP because they occur with relatively high frequency. Most patients suffer from some impairment of dark adaptation, visual field loss, and pain. Pain during laser treatment is highly variable and depends on characteristics of both the laser and the patient. Importantly, adherence to recommended PRP schedules depends on the patients' willingness to return. Often times, patients will require retrobulbar or peribulbar anesthesia to complete treatment. Other less common, but more serious, reported complications of PRP include corneal abrasions, mydriasis due to damage of nerves, macular edema, choroidal detachment or hemorrhage, exudative retinal detachment, subretinal neovascularization, vitreous hemorrhage from regression of neovascular tissue, lens opacities, and vascular occlusions.
New Laser Technologies for Diabetic Retinopathy

Following Moore's law, the introduction of lasers to ophthalmology resulted in a proliferation of increasingly sophisticated delivery systems. The newest lasers on the block are those using automated delivery technologies to increase accuracy of retinal ablation, decrease pain by optimizing pulse intensity and duration, and reducing the number of treatment sessions required. These include the pattern scanning photocoagulator (PASCAL ${ }^{\circledR}$ ) and navigated laser $\left(\mathrm{NAVILAS}^{\circledR}\right)$. Sublethal retinal phototherapy with the SDM laser for diabetic macular edema has challenged the underlying paradigm of retinal laser photocoagulation treatment by demonstrating that retinal damage is not necessary for the treatment of macular edema and other retinovascular disorders. Here, we will review the current literature on these new laser therapies.

\section{PAttern-SCAnning Laser (PASCAL ${ }^{\circledR}$ )}

In 2005, the first semi-automated laser therapy for retinal diseases was introduced-the PASCAL ${ }^{\circledR}$ pattern-scanning photocoagulator (OptiMedica; Topcon Medical Laser Systems, Santa Clara, CA, USA) [45••]. PASCAL ${ }^{\circledR}$ can rapidly deliver various patterns of 532-nm laser pulses (56 spots in $0.6 \mathrm{~s}$ ) with the depression of a foot pedal that can be controlled by the physician (Fig. 1). The laser settings are manipulated with a touch screen graphic user interface that allows flexibility based on clinical judgment and conditions being treated (Fig. 1a). Predetermined photocoagulation patterns include arcs with concentric rows, circles for small holes, square arrays for PDR, and standard single-spot photocoagulation (Fig. 1b).

PASCAL $^{\circledR}$ aims to address the shortcomings of manual laser therapy: pain, thermal blooming from heat diffusion, inadvertent photocoagulation of adjacent tissues, the inconvenience of multiple sessions, and the time required to perform treatment. The indications for retinal photocoagulation with PASCAL ${ }^{\circledR}$ are the same as those for traditional slit-lamp photocoagulation. The laser delivers the entire treatment in one sitting by using shorter exposure duration than conventional photocoagulation (10-20 vs. 100-200 ms). The shorter exposure duration is the primary driver of the benefits of PASCAL ${ }^{\circledR}$ because it reduces heat diffusion in the retina resulting in limited thermal blooming and, thus, the patient experiences less pain $[46,47]$. Studies report that patients prefer single session PRP with to traditional multi-session single-spot argon laser treatments and that PASCAL ${ }^{\circledR}$ laser produces less anxiety, fewer headaches, and is well tolerated with topical anesthesia alone [48-50].

The Manchester Pascal Study randomized 40 eyes with PDR and compared conventional single-spot multi-session 


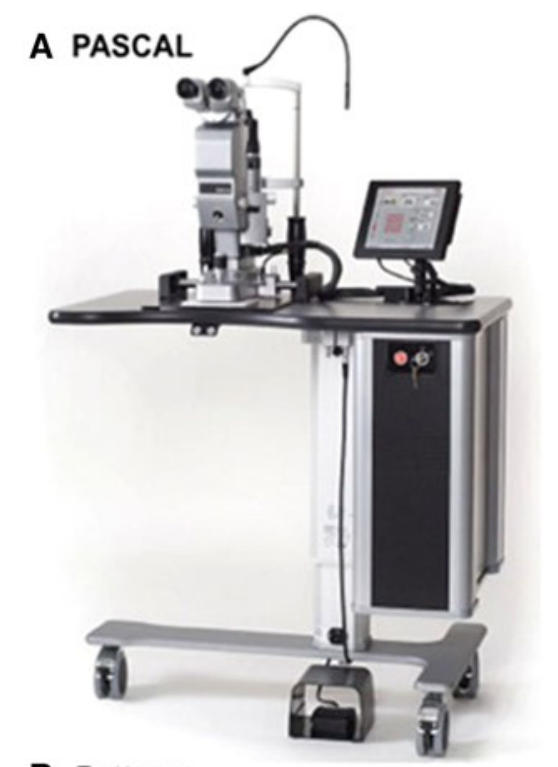

B Patterns

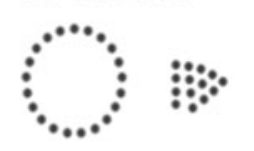

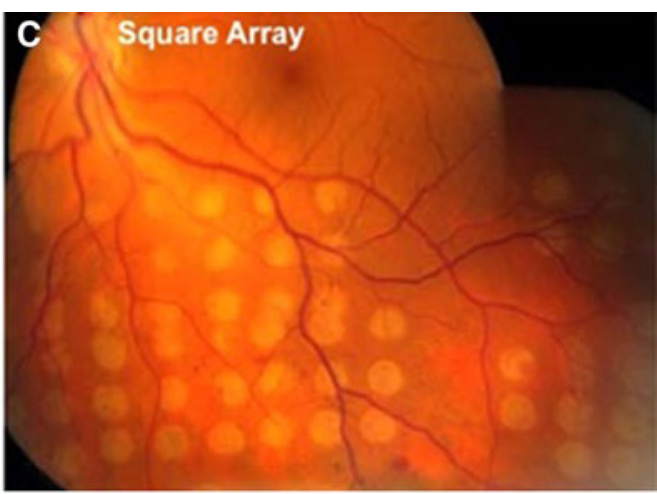

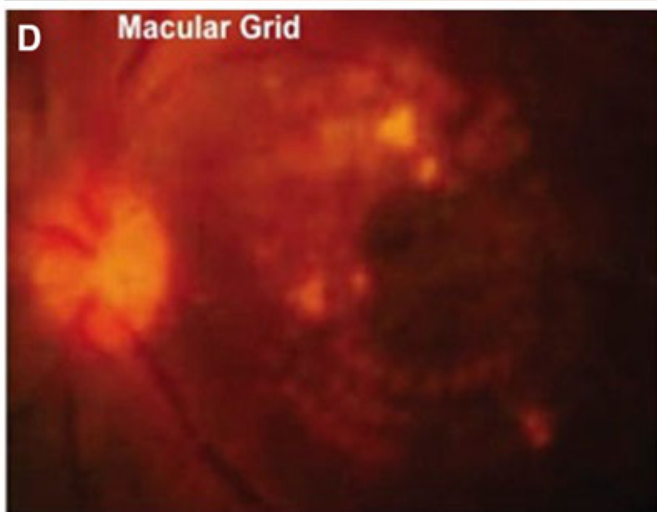

also be set to $2 \times 2,4 \times 4$, and $5 \times 5$. d Comparing conventional with pattern laser treatment with a macular grid for clinically significant diabetic macular edema. The extrafoveal burns on the superonasal hemisphere are conventional single spot treatment while the burns on the lower, inferotemporal extrafoveal region were performed with PASCAL $^{\circledR}$. All photos were reproduced with permission from the makers of the pattern-scanning photocoagulator: Topcon Medical Laser Systems (Santa Clara, CA, USA)

properly powered longitudinal studies will be necessary to understand the efficacy and effectiveness of this new technology for retinal therapy in the long run.

\section{NAVIgated LASer $\left(\right.$ NAVILAS $\left.^{\circledR}\right)$}

In 2009, the first retinal navigation device was approved by the FDA for the treatment of retinal disorders-the NAVILAS ${ }^{\circledR}$ laser system (OD-OS Retina Navigation, Germany). The technology incorporates wide-field fundus viewing and eye tracking and integrates multiple imaging modalities, such as OCT and fluorescein angiogram (FA), to improve the ease and accuracy of retinal photocoagulation. NAVILAS ${ }^{\circledR}$ can be used for a variety of retinal disorders with three primary settings: focal, multimodal, and PRP, with an automated 532-nm laser of variable intensity, fluence, and duration.

The NAVILAS ${ }^{\circledR}$ laser system was developed to improve the accuracy of laser photocoagulation delivery. By combining a diagnostic camera system with the therapeutic 
laser, the physician is able to image, plan, and treat a patient with one device. The device offers four real-time retinal imaging modalities: (1) true-color mydriatic FA, (2) non-mydriatic FA, (3) infrared, and (4) red-free. With these features, the physician can image, plan, and treat in one rapidly adapting platform. As the patient fixates, the images can be used to create a treatment plan with highlighted markers of target areas overlying real-time images to assist and document precise delivery of photocoagulation. The eye tracking software ensures that automated photocoagulation only proceeds when the patients' eye is in position, with an automatic disarm when the eye loses fixation. Thus, the physician can rapidly and accurately delivery laser treatment with automated patterns, but the device has safeguards to prevent inadvertent photocoagulation. The pulse duration can be manipulated from 10 to over $100 \mathrm{~ms}$ based on physician preferences and indication. During the process, the physician can also record the treatment for documentation and teaching.

Published studies using NAVILAS ${ }^{\circledR}$ are limited likely due to the relatively recent release. The two largest studies with NAVILAS ${ }^{\circledR}$ were performed by Kozak et al. [61, 62•], in which series of patients with diabetic retinopathy and diabetic macular edema underwent NAVILAS ${ }^{\circledR}$ therapy. They concluded that NAVILAS ${ }^{\circledR}$ was safe and had better accuracy of retinal photocoagulation when compared with a retrospective review of argon laser therapy. Patients treated had significant improvements in visual acuity and significantly decreased OCT measures of thickness, and reported less pain when compared with traditional argon PRP [61, 62•]. Two other pilot studies have found similar results in terms of safety, outcomes in diabetic macular edema, and reduction of pain [63, 64]. There are no published studies evaluating navigated laser photocoagulation in the long run, and there are no head-to-head trials of the two automated lasers.

\section{SMD Laser}

Over the last four decades, CSME has been managed with focal/grid photocoagulation based on demonstrated vision benefits in the ETDRS [26••]. Like other lasers for the retina, the long-held paradigm in administration of focal photocoagulation has been that iatrogenic retinal damage is necessary and acceptable given the significant visual acuity benefits in CSME. Over time, the lasers have become less intense, more accurate, and more precise in their ablation to the extent that the original notion of necessary retinal damage was questioned with the first near-infrared 810-nm diode laser that was micropulsed, rather than administered continuously, for treatment of CSME [65, 66॰]. This new technology uses a longer wavelength (lower energy) and is administered in micropulses that reduces the thermal damage on the retinal to nearly undetectable levels. The introduction of this technology with early reports of equivalent efficacy gave rise to the concept of invisible retinal phototherapy.

Initial case intervention studies comparing SDM laser to traditional focal argon laser in the ETDRS demonstrated promising results-reporting similar efficacy and effectiveness for treatment of macular edema using invisible, or sublethal, retinal phototherapy [65, 67-71]. Since its introduction in the mid-1990s, four clinical trials have compared SDM laser to traditional argon laser for CSME, with outcome measures including the final best corrected visual acuity, relevant OCT measures including retinal thickness, safety, and multifocal electroretinography (mfERG) recordings, to assess remaining retinal functionality after treatment $[68,72 \cdot, 73,74]$. These studies have all reported that SDM is equally efficacious for the treatment of diabetic macular edema when compared to traditional Nd:YAG laser [70, 71]. Venkatesh et al. [74] assessed differences in final retinal function with mfERG and found that SDM results in significantly increased remaining retinal function, and these results have been replicated in other studies [75] SDM has also demonstrated good longterm safety profiles [76]. Reviews of this SDM technology for retinal phototherapy have found it to be a clinically effective and nearly harmless treatment for diabetic macular edema as well as other disorders [77, 78].

The discovery that macular edema and proliferative retinopathy can be treated without concomitant retinal damage has fundamentally changed our understanding of retinal disease. The exact mechanism of sublethal therapy for retinal photocoagulation remains to be unraveled, but offers a new arena of investigation for treatment of diabetic eye disease and other retinal disorders that could improve patient outcomes and further reduce adverse effects. In patients with CSME, SDM laser photocoagulation offers similar treatment efficacy with regard to final visual acuity outcomes with minimal retinal damage. Further, because of the invisible retinal phototherapy and ability to repeat the treatment, the SDM laser is particularly appealing for treatment near the fovea. However, the invisible phototherapy also makes monitoring of serial treatments difficult due to lack of reliable dosimetry making the treatment difficult to standardize across centers. Ohkoshi et al. [79] recently reported that scanning laser ophthalmoscopy in retro-mode could be used to detect sites of SDM application for treatment tracking. This may offer some relief to the issue of tracking treatments, but needs more research supporting its use as a monitoring modality. The primary limitation of wide SDM adoption is the emergence of primary pharmacologic therapy with intravitreal injections that may entirely replace focal laser therapy as first-line treatment for CSME. 


\section{Conclusions}

One in ten Americans has systemic diabetes, and the Center for Disease Control and Prevention predicts that over the coming decades the number will rapidly increase to between one in five and one in three by 2050 , based on current trends $[80,81]$. This reflects shortcomings in the diagnosis, follow-up, screening, and limitations in current treatment of systemic diabetes. Although the metabolic derangement has direct effects on the neurons and support cells of the retina, the retinal vascular changes dominate the clinical manifestations of the ocular disease and are directly implicated in macular edema and neovascularization that represent the principal causes of vision loss. The ocular complications arising from PDR remain a leading cause of severe, irreversible visual impairment in developing countries [82]. Properly controlling a patients' glucose, blood pressure, and lipids is critical for not only preventing development of retinopathy but also maximizing the efficacy of treatment [83].

Over the past 50 years, we have made leaps and bounds in the treatment of diabetic eye disease. Advances in automated laser technology systems have resulted in faster, safer, more accurate, and less painful treatment when compared to manual single-spot lasers. SDM laser therapy now has multiple level one studies supporting the efficacy of sublethal therapy for the treatment of macular edema and has altered our fundamental understanding of retinal photocoagulation. Advances in pharmacologic therapy using anti-VEGF agents have yielded unprecedented vision outcomes for diabetic macular edema. These new pharmacologic therapies have revolutionized the field of ophthalmology and offer significant reductions in vision loss when compared to laser alone, but the long-term outcome with these treatments is still being unraveled. Further, intravitreal injections are an unpleasant experience for patients and are often anxiety-provoking-how will the long-term delivery of VEGF antagonists develop and how will these be incorporated with the established efficacy of laser treatments? The research does not keep up with the innovation in either of these fields, and we are left to contemplate what the optimal treatment strategy for an individual patient sitting in the examination room will be with an arsenal of new treatments, but limited data, on their use.

The establishment of standard treatment algorithms incorporating these evolving pharmacologic and laser technologies is difficult but necessary to determine an evidence-based integration of treatments, including the dose (for injections), schedule, and frequency. Overall, the rapid evolution of therapy for diabetic retinopathy offers hope to the millions suffering from vision loss. The new lasers discussed in this review will likely be adopted as the new standard because of their many benefits, and two of them are already widely used in the USA, including our home clinic at Stanford. Long-term, well-designed, longitudinal trial data are needed to answer the many questions about the newest laser therapies before we can give a final verdict on for their use in the treatment of diabetic retinopathy.

Disclosures Natalia Fijalkowski declares no conflict of interest. Darius M. Moshfeghi is a consultant to Oraya Therapeutics, Genentech, and Synergetics, has stock/stock options with Realm Global, Convene, and Versa Vision, and received travel/accommodations expenses covered or reimbursed by Bager.

Human and Animal Rights and Informed Consent This article does not contain any studies with human or animal subjects performed by any of the authors.

\section{References}

Papers of particular interest, published recently, have been highlighted as:

- Of importance

•- Of major importance

1. Zhang X, Saaddine JB, Chou CF, Cotch MF, Cheng YJ, Geiss LS, et al. Prevalence of diabetic retinopathy in the United States, 2005-2008. J Am Med Assoc. 2010;304(6):649-56. doi:10.1001/ jama.2010.1111.

2. Congdon N, O'Colmain B, Klaver CC, Klein R, Munoz B, Friedman DS, et al. Causes and prevalence of visual impairment among adults in the United States. Arch Ophthalmol. 2004; 122(4):477-85. doi:10.1001/archopht.122.4.477.

3. Fijalkowski N, Pershing S, Moshfeghi DM. The importance of keeping a broad differential in retina clinic: the spectrum of ophthalmic disease seen by retina specialists in a tertiary outpatient clinic setting. Ophthalmic Surg Lasers Imaging Retin. 2013;44(2):133-9. doi:10.3928/23258160-20130313-06.

4. American Diabetes Association. Standards of medical care in diabetes-2012. Diabetes Care. 2012;35(Suppl 1):S11-63. doi: 10.2337/dc12-s011.

5. Mohamed Q, Gillies MC, Wong TY. Management of diabetic retinopathy: a systematic review. J Am Med Assoc. 2007;298(8): 902-16. doi:10.1001/jama.298.8.902.

6. Klein R, Knudtson MD, Lee KE, Gangnon R, Klein BE. The Wisconsin Epidemiologic Study of Diabetic Retinopathy: XXII the twenty-five-year progression of retinopathy in persons with type 1 diabetes. Ophthalmology. 2008;115(11):1859-68. doi:10. 1016/j.ophtha.2008.08.023.

7. Cikamatana L, Mitchell P, Rochtchina E, Foran S, Wang JJ. Fiveyear incidence and progression of diabetic retinopathy in a defined older population: the Blue Mountains Eye Study. Eye. 2007;21(4):465-71. doi:10.1038/sj.eye.6702771.

8. Raman R, Gupta A, Krishna S, Kulothungan V, Sharma T. Prevalence and risk factors for diabetic microvascular complications in newly diagnosed type II diabetes mellitus. Sankara Nethralaya Diabetic Retinopathy Epidemiology and Molecular Genetic Study (SN-DREAMS, Report 27). J Diabetes Complicat. 2012;26(2):123-8. doi:10.1016/j.jdiacomp.2012.02.001. 
9. Leske MC, Wu SY, Hennis A, Hyman L, Nemesure B, Yang L, et al. Hyperglycemia, blood pressure, and the 9-year incidence of diabetic retinopathy: the Barbados Eye Studies. Ophthalmology. 2005;112(5):799-805. doi:10.1016/j.ophtha.2004.11.054.

10. Pedro RA, Ramon SA, Marc BB, Juan FB, Isabel MM. Prevalence and relationship between diabetic retinopathy and nephropathy, and its risk factors in the North-East of Spain, a population-based study. Ophthalmic Epidemiol. 2010;17(4):251-65. doi:10.3109/ 09286586.2010.498661.

11. Schrier RW, Estacio RO, Esler A, Mehler P. Effects of aggressive blood pressure control in normotensive type 2 diabetic patients on albuminuria, retinopathy and strokes. Kidney Int. 2002;61(3): 1086-97. doi:10.1046/j.1523-1755.2002.00213.x.

12. Progression of retinopathy with intensive versus conventional treatment in the Diabetes Control and Complications Trial. Diabetes Control and Complications Trial Research Group. Ophthalmology. 1995;102(4):647-61.

13. Tight blood pressure control and risk of macrovascular and microvascular complications in type 2 diabetes: UKPDS 38. UK Prospective Diabetes Study Group. BMJ. 1998;317(7160):703-13.

14. Matthews DR, Stratton IM, Aldington SJ, Holman RR, Kohner EM, UKPDS Group. Risks of progression of retinopathy and vision loss related to tight blood pressure control in type 2 diabetes mellitus: UKPDS 69. Arch Ophthalmol. 2004;122(11): 1631-40. doi:10.1001/archopht.122.11.1631.

15. Klein R. Hyperglycemia and microvascular and macrovascular disease in diabetes. Diabetes Care. 1995;18(2):258-68.

16. Photocoagulation treatment of proliferative diabetic retinopathy. Clinical application of Diabetic Retinopathy Study (DRS) findings, DRS Report Number 8. The Diabetic Retinopathy Study Research Group. Ophthalmology. 1981;88(7):583-600.

17. Okun E, Johnston GP, Boniuk I, Arribas NP, Escoffery RF, Grand MG. Xenon arc photocoagulation of proliferative diabetic retinopathy. A review of 2688 consecutive eyes in the format of the Diabetic Retinopathy Study. Ophthalmology. 1984;91(12): $1458-63$.

18. • Early photocoagulation for diabetic retinopathy. ETDRS Report Number 9. Early Treatment Diabetic Retinopathy Study Research Group. Ophthalmology. 1991;98(5 Suppl):766-85. This paper established early laser therapy as the first line treatment for diabetic retinopathy.

19. Toussaint D, Dustin P. Electron microscopy of normal and diabetic retinal capillaries. Arch Ophthalmol. 1963;70:96-108.

20. Speiser P, Gittelsohn AM, Patz A. Studies on diabetic retinopathy. 3. Influence of diabetes on intramural pericytes. Arch Ophthalmol. 1968;80(3):332-7.

21. Aguilar E, Friedlander M, Gariano RF. Endothelial proliferation in diabetic retinal microaneurysms. Arch Ophthalmol. 2003; 121(5):740-1. doi:10.1001/archopht.121.5.740.

22. Klein R, Klein BE, Moss SE. How many steps of progression of diabetic retinopathy are meaningful? The Wisconsin Epidemiologic Study of Diabetic Retinopathy. Arch Ophthalmol. 2001; 119(4):547-53.

23. Aiello LM. Perspectives on diabetic retinopathy. Am J Ophthalmol. 2003;136(1):122-35.

24. Wilkinson CP, Ferris FL III, Klein RE, Lee PP, Agardh CD, Davis $\mathrm{M}$, et al. Proposed international clinical diabetic retinopathy and diabetic macular edema disease severity scales. Ophthalmology. 2003;110(9):1677-82. doi:10.1016/S0161-6420(03) 00475-5.

25. Lovestam-Adrian M, Agardh CD, Torffvit O, Agardh E. Type 1 diabetes patients with severe non-proliferative retinopathy may benefit from panretinal photocoagulation. Acta Ophthalmol Scand. 2003;81(3):221-5.

26. •• Photocoagulation for diabetic macular edema. Early Treatment Diabetic Retinopathy Study Report Number 1. Early Treatment
Diabetic Retinopathy Study Research Group. Arch Ophthalmol. 1985;103(12):1796-806. This paper established the efficacy of early focal photocoagulation for diabetic macular edema.

27. Jorge R, Costa RA, Calucci D, Cintra LP, Scott IU. Intravitreal bevacizumab (Avastin) for persistent new vessels in diabetic retinopathy (IBEPE Study). Retina. 2006;26(9):1006-13. doi:10. 1097/01.iae.0000246884.76018.63.

28. Avery RL. Regression of retinal and iris neovascularization after intravitreal bevacizumab (Avastin) treatment. Retina. 2006;26(3): $352-4$.

29. Chen E, Park CH. Use of intravitreal bevacizumab as a preoperative adjunct for tractional retinal detachment repair in severe proliferative diabetic retinopathy. Retina. 2006;26(6):699-700. doi:10.1097/01.iae.0000225351.87205.69.

30. • Mitchell P, Bandello F, Schmidt-Erfurth U, Lang GE, Massin P, Schlingemann RO, et al. The RESTORE study: ranibizumab monotherapy or combined with laser versus laser monotherapy for diabetic macular edema. Ophthalmology. 2011;118(4):615-25. doi:10.1016/j.ophtha.2011.01.031. This large, randomized clinical trial compared intravitreal ranibizumab with and without laser.

31. Salam A, DaCosta J, Sivaprasad S. Anti-vascular endothelial growth factor agents for diabetic maculopathy. Br J Ophthalmol. 2010;94(7):821-6. doi:10.1136/bjo.2009.163576.

32. Cunningham ET Jr, Adamis AP, Altaweel M, Aiello LP, Bressler NM, D'Amico DJ, et al. A phase II randomized double-masked trial of pegaptanib, an anti-vascular endothelial growth factor aptamer, for diabetic macular edema. Ophthalmology. 2005; 112(10):1747-57. doi:10.1016/j.ophtha.2005.06.007.

33. Massin P, Bandello F, Garweg JG, Hansen LL, Harding SP, Larsen $\mathrm{M}$, et al. Safety and efficacy of ranibizumab in diabetic macular edema (RESOLVE Study): a 12-month, randomized, controlled, double-masked, multicenter phase II study. Diabetes Care. 2010;33(11):2399-405. doi:10.2337/dc10-0493.

34. Virgili G, Parravano M, Menchini F, Brunetti M. Antiangiogenic therapy with anti-vascular endothelial growth factor modalities for diabetic macular oedema. Cochrane Database Syst Rev. 2012;12:CD007419. doi:10.1002/14651858.CD007419.pub3.

35. • Diabetic Retinopathy Clinical Research Network, Elman MJ, Qin H, Aiello LP, Beck RW, Bressler NM, et al. Intravitreal ranibizumab for diabetic macular edema with prompt versus deferred laser treatment: three-year randomized trial results. Ophthalmology. 2012;119(11):2312-8. doi:10.1016/j.ophtha.2012. 08.022. This study compared intravitreal ranibizumab with prompt vs. deferred laser and found intravitreal treatment with deferred laser had the best visual acuity gains reported in the diabetic macular edema literature.

36. Four risk factors for severe visual loss in diabetic retinopathy. The third report from the Diabetic Retinopathy Study. The Diabetic Retinopathy Study Research Group. Arch Ophthalmol. 1979;97(4):654-5.

37. Klein R, Klein BE, Moss SE, Davis MD, DeMets DL. The Wisconsin Epidemiologic Study of Diabetic Retinopathy. III. Prevalence and risk of diabetic retinopathy when age at diagnosis is 30 or more years. Arch Ophthalmol. 1984;102(4):527-32.

38. Klein R, Klein BE, Moss SE, Davis MD, DeMets DL. The Wisconsin Epidemiologic Study of Diabetic Retinopathy. II. Prevalence and risk of diabetic retinopathy when age at diagnosis is less than 30 years. Arch Ophthalmol. 1984;102(4):520-6.

39. Photocoagulation treatment of proliferative diabetic retinopathy: the second report of diabetic retinopathy study findings. Ophthalmology. 1978;85(1):82-106.

40. Sramek C, Paulus Y, Nomoto H, Huie P, Brown J, Palanker D. Dynamics of retinal photocoagulation and rupture. Journal Biomed Opt. 2009;14(3):034007. doi:10.1117/1.3130282.

41. Fong DS, Segal PP, Myers F, Ferris FL, Hubbard LD, Davis MD. Subretinal fibrosis in diabetic macular edema. ETDRS Report 23. 
Early Treatment Diabetic Retinopathy Study Research Group. Arch Ophthalmol. 1997;115(7):873-7.

42. Network DRCR. Modified-ETDRS focal photocoagulation technique. 2011. http://drcrnet.jaeb.org/Studies.aspx. Accessed 11 Nov 2011.

43. Hercules BL, Gayed II, Lucas SB, Jeacock J. Peripheral retinal ablation in the treatment of proliferative diabetic retinopathy: a three-year interim report of a randomised, controlled study using the argon laser. Br J Ophthalmol. 1977;61(9):555-63.

44. Photocoagulation for proliferative diabetic retinopathy: a randomised controlled clinical trial using the xenon-arc. Diabetologia. 1984;26(2):109-15.

45. •• Blumenkranz MS, Yellachich D, Andersen DE, Wiltberger MW, Mordaunt D, Marcellino GR, et al. Semiautomated patterned scanning laser for retinal photocoagulation. Retina. 2006;26(3):370-6. This paper is the first to describe the PASCAL laser for semi-automated retinal photocoagulation.

46. Modi D, Chiranand P, Akduman L. Efficacy of patterned scan laser in treatment of macular edema and retinal neovascularization. Clin Ophthalmol. 2009;3:465-70.

47. Muqit MM, Gray JC, Marcellino GR, Henson DB, Young LB, Patton $\mathrm{N}$, et al. In vivo laser-tissue interactions and healing responses from 20- vs 100-millisecond pulse Pascal photocoagulation burns. Arch Ophthalmol. 2010;128(4):448-55. doi:10. 1001/archophthalmol.2010.36.

48. Muraly P, Limbad P, Srinivasan K, Ramasamy K. Single session of Pascal versus multiple sessions of conventional laser for panretinal photocoagulation in proliferative diabetic retinopathy: a comparative study. Retina. 2011;31(7):1359-65. doi:10.1097/ IAE.0b013e318203c140.

49. Muqit MM, Marcellino GR, Gray JC, McLauchlan R, Henson DB, Young LB, et al. Pain responses of Pascal 20 ms multi-spot and $100 \mathrm{~ms}$ single-spot panretinal photocoagulation: Manchester Pascal Study, MAPASS Report 2. Br J Ophthalmol. 2010; 94(11):1493-8. doi:10.1136/bjo.2009.176677.

50. Nagpal M, Marlecha S, Nagpal K. Comparison of laser photocoagulation for diabetic retinopathy using 532-nm standard laser versus multispot pattern scan laser. Retina. 2010;30(3):452-8. doi:10.1097/IAE.0b013e3181c70127.

51. Muqit MM, Marcellino GR, Henson DB, Fenerty CH, Stanga PE. Randomized clinical trial to evaluate the effects of Pascal panretinal photocoagulation on macular nerve fiber layer: Manchester Pascal Study Report 3. Retina. 2011;31(8):1699-707. doi:10.1097/IAE.0b013e318207d188.

52. Muqit MM, Marcellino GR, Henson DB, Young LB, Patton N, Charles SJ, et al. Optos-guided pattern scan laser (Pascal)-targeted retinal photocoagulation in proliferative diabetic retinopathy. Acta Ophthalmol. 2013;91(3):251-8. doi:10.1111/j.17553768.2011.02307.x.

53. - Muqit MM, Marcellino GR, Henson DB, Young LB, Turner GS, Stanga PE. Pascal panretinal laser ablation and regression analysis in proliferative diabetic retinopathy: Manchester Pascal Study Report 4. Eye. 2011;25(11):1447-56. doi:10.1038/eye.2011.188. This paper is the largest, randomized clinical trial evaluating PASCAL laser treatment vs. conventional laser and found PASCAL to be equivalent in terms of saftey and outcomes, while superior when assessing patient pain and comfort.

54. Sheth S, Lanzetta P, Veritti D, Zucchiatti I, Savorgnani C, Bandello F. Experience with the Pascal(R) photocoagulator: an analysis of over 1,200 laser procedures with regard to parameter refinement. Indian J Ophthalmol. 2011;59(2):87-91. doi:10.4103/ 0301-4738.77007.

55. Sanghvi C, McLauchlan R, Delgado C, Young L, Charles SJ, Marcellino G, et al. Initial experience with the Pascal photocoagulator: a pilot study of 75 procedures. $\mathrm{Br} \mathrm{J}$ Ophthalmol. 2008;92(8):1061-4. doi:10.1136/bjo.2008.139568.
56. Velez-Montoya R, Guerrero-Naranjo JL, Gonzalez-Mijares CC, Fromow-Guerra J, Marcellino GR, Quiroz-Mercado H, et al. Pattern scan laser photocoagulation: safety and complications, experience after 1301 consecutive cases. $\mathrm{Br} \mathrm{J}$ Ophthalmol. 2010;94(6):720-4. doi:10.1136/bjo.2009.164996.

57. Muqit MM, Gray JC, Marcellino GR, Henson DB, Young LB, Patton N, et al. Barely visible 10-millisecond pascal laser photocoagulation for diabetic macular edema: observations of clinical effect and burn localization. Am J Ophthalmol. 2010;149(6):979-86 e2. doi:10.1016/j.ajo.2010.01.032.

58. Muqit MM, Sanghvi C, McLauchlan R, Delgado C, Young LB, Charles SJ, et al. Study of clinical applications and safety for Pascal(R) laser photocoagulation in retinal vascular disorders. Acta Ophthalmol. 2012;90(2):155-61. doi:10.1111/j.1755-3768. 2009.01854.x.

59. Jain A, Collen J, Kaines A, Hubschman JP, Schwartz S. Shortduration focal pattern grid macular photocoagulation for diabetic macular edema: four-month outcomes. Retina. 2010;30(10): 1622-6. doi:10.1097/IAE.0b013e3181e095d8.

60. Muqit MM, Young LB, McKenzie R, John B, Marcellino GR, Henson DB, et al. Pilot randomised clinical trial of Pascal TargETEd Retinal versus variable fluence PANretinal $20 \mathrm{~ms}$ laser in diabetic retinopathy: PETER PAN Study. Br J Ophthalmol. 2013;97(2):220-7. doi:10.1136/bjophthalmol-2012-302189.

61. Kozak I, Kim JS, Oster SF, Chhablani J, Freeman WR. Focal navigated laser photocoagulation in retinovascular disease: clinical results in initial case series. Retina. 2012;32(5):930-5. doi:10.1097/IAE.0b013e318227ab5b.

62. - Kozak I, Oster SF, Cortes MA, Dowell D, Hartmann K, Kim JS, et al. Clinical evaluation and treatment accuracy in diabetic macular edema using navigated laser photocoagulator NAVILAS. Ophthalmology. 2011;118(6):1119-24. doi:10.1016/j.ophtha. 2010.10.007. This is one of the few large prospective studies using NAVILAS to treat diabetic macular edema and found equivalent safety and vision outcomes with reduced pain and increased patient satisfaction.

63. Kernt M, Cheuteu RE, Cserhati S, Seidensticker F, Liegl RG, Lang J, et al. Pain and accuracy of focal laser treatment for diabetic macular edema using a retinal navigated laser (Navilas). Clin Ophthalmol. 2012;6:289-96. doi:10.2147/OPTH. S27859.

64. Chalam KV, Murthy RK, Brar V, Radhakrishnan R, Khetpal V, Grover S. Evaluation of a Novel, Non Contact, Automated Focal Laser with Integrated (NAVILAS) Fluorescein Angiography for Diabetic Macular Edema. Middle East Afr J Ophthalmol. 2012;19(1):158-62. doi:10.4103/0974-9233.92134.

65. Friberg TR, Karatza EC. The treatment of macular disease using a micropulsed and continuous wave 810-nm diode laser. Ophthalmology. 1997;104(12):2030-8.

66. - Pankratov MM. Pulsed delivery of laser energy in experimental thermal retinal photocoagulation. In: Proceedings SPIE 1202, Laser-Tissue Interaction; 1990. p. 205-13. This is the first explanation of subthreshold diode micropulsed laser in the literature that has since been adapted.

67. Luttrull JK, Musch DC, Mainster MA. Subthreshold diode micropulse photocoagulation for the treatment of clinically significant diabetic macular oedema. Br J Ophthalmol. 2005;89(1): 74-80. doi:10.1136/bjo.2004.051540.

68. Figueira J, Khan J, Nunes S, Sivaprasad S, Rosa A, de Abreu JF, et al. Prospective randomised controlled trial comparing subthreshold micropulse diode laser photocoagulation and conventional green laser for clinically significant diabetic macular oedema. Br J Ophthalmol. 2009;93(10):1341-4. doi:10.1136/bjo. 2008.146712.

69. Sivaprasad S, Sandhu R, Tandon A, Sayed-Ahmed K, McHugh DA. Subthreshold micropulse diode laser photocoagulation for 
clinically significant diabetic macular oedema: a three-year follow up. Clin Exp Ophthalmol. 2007;35(7):640-4. doi:10.1111/j. 1442-9071.2007.01566.x.

70. Takatsuna Y, Yamamoto S, Nakamura Y, Tatsumi T, Arai M, Mitamura Y. Long-term therapeutic efficacy of the subthreshold micropulse diode laser photocoagulation for diabetic macular edema. Jpn J Ophthalmol. 2011;55(4):365-9. doi:10.1007/ s10384-011-0033-3.

71. Ohkoshi K, Yamaguchi T. Subthreshold micropulse diode laser photocoagulation for diabetic macular edema in Japanese patients. Am J Ophthalmol. 2010;149(1):133-9. doi:10.1016/j. ajo.2009.08.010.

72. - Vujosevic S, Bottega E, Casciano M, Pilotto E, Convento E, Midena E. Microperimetry and fundus autofluorescence in diabetic macular edema: subthreshold micropulse diode laser versus modified early treatment diabetic retinopathy study laser photocoagulation. Retina. 2010;30(6):908-16. doi:10.1097/IAE. 0b013e3181c96986. This study evaluated subthreshold micropulse diode laser with conventional treatment for macular edema and found equivalent safety and vision outcomes with greatly improved retinal functionality after treatment in the subthreshold laser group.

73. Lavinsky D, Cardillo JA, Melo LA Jr, Dare A, Farah ME, Belfort R Jr. Randomized clinical trial evaluating mETDRS versus normal or high-density micropulse photocoagulation for diabetic macular edema. Investig Ophthalmol Vis Sci. 2011;52(7):431423. doi:10.1167/iovs.10-6828.

74. Venkatesh P, Ramanjulu R, Azad R, Vohra R, Garg S. Subthreshold micropulse diode laser and double frequency neodymium: YAG laser in treatment of diabetic macular edema: a prospective, randomized study using multifocal electroretinography. Photomed Laser Surg. 2011;29(11):727-33. doi:10.1089/ pho.2010.2830

75. Nakamura Y, Mitamura Y, Ogata K, Arai M, Takatsuna Y, Yamamoto $\mathrm{S}$. Functional and morphological changes of macula after subthreshold micropulse diode laser photocoagulation for diabetic macular oedema. Eye. 2010;24(5):784-8. doi:10.1038/eye. 2009.207.

76. Luttrull JK, Sramek C, Palanker D, Spink CJ, Musch DC. Longterm safety, high-resolution imaging, and tissue temperature modeling of subvisible diode micropulse photocoagulation for retinovascular macular edema. Retina. 2012;32(2):375-86. doi: 10.1097/IAE.0b013e3182206f6c.

77. Luttrull JK, Dorin G. Subthreshold diode micropulse laser photocoagulation (SDM) as invisible retinal phototherapy for diabetic macular edema: a review. Curr Diabetes Rev. 2012;8(4): 274-84.

78. Sivaprasad S, Dorin G. Subthreshold diode laser micropulse photocoagulation for the treatment of diabetic macular edema. Expert Rev Med Devices. 2012;9(2):189-97. doi:10.1586/erd.12.1.

79. Ohkoshi K, Tsuiki E, Kitaoka T, Yamaguchi T. Visualization of subthreshold micropulse diode laser photocoagulation by scanning laser ophthalmoscopy in the retro mode. Am J Ophthalmol. 2010;150(6):856-62. doi:10.1016/j.ajo.2010.06.022.

80. National diabetes fact sheet: national estimates and general information on diabetes and prediabetes in the United States, 2011. U.S. Department of Health and Human Services, Atlanta, GA, 2011.

81. Boyle JP, Thompson TJ, Gregg EW, Barker LE, Williamson DF. Projection of the year 2050 burden of diabetes in the US adult population: dynamic modeling of incidence, mortality, and prediabetes prevalence. Popul Health Metr. 2010;8:29. doi:10.1186/ 1478-7954-8-29.

82. Wong TY, Mwamburi M, Klein R, Larsen M, Flynn H, HernandezMedina M, et al. Rates of progression in diabetic retinopathy during different time periods: a systematic review and meta-analysis. Diabetes Care. 2009;32(12):2307-13. doi:10.2337/dc09-0615.

83. Kotoula MG, Koukoulis GN, Zintzaras E, Karabatsas $\mathrm{CH}$, Chatzoulis DZ. Metabolic control of diabetes is associated with an improved response of diabetic retinopathy to panretinal photocoagulation. Diabetes Care. 2005;28(10):2454-7.

84. Grading diabetic retinopathy from stereoscopic color fundus photographs - an extension of the modified Airlie House classification. ETDRS Report Number 10. Early Treatment Diabetic Retinopathy Study Research Group. Ophthalmology. 1991;98(5 Suppl):786-806.

85. Fundus photographic risk factors for progression of diabetic retinopathy. ETDRS Report Number 12. Early Treatment Diabetic Retinopathy Study Research Group. Ophthalmology. 1991; 98(5 Suppl):823-33. 